\title{
latrogenic ureteric injuries in urological surgeries- A Tertiary hospital experience.
}

1. MBBS, FCPS (Urology), FCPS (Surgery)

Associate Professor Urology Jinnah Postgraduate Medical Centre Karachi.

Correspondence Address:

Dr. Muhammad Mansoor

Flat No. C-5, Category- III, Doctors Colony

Jinnah Postgraduate Medical Centre Karachi

mansuryaqub@hotmail.com

Article received on: 30/06/2020

Accepted for publication: $03 / 08 / 2020$

\section{Muhammad Mansoor ${ }^{1}$}

ABSTRACT... Objectives: To review our experience in the management of iatrogenic ureter injuries caused by different urological procedures. Study Design: Descriptive Case series. Setting: Department of Urology, Jinnah Postgraduate Medical Centre Karachi. Period: January 2011 to December 2018. Material \& Methods: We included all cases of iatrogenic ureteric injuries induced by urology department only. Gynecological and general surgical iatrogenic injuries were excluded in this study. Results: We managed 56 iatrogenic ureteric injuries in 47 patients during study period. Mean age was $43.14+8.86$ years. There were 31 males $(66 \%)$ and 16 females (34\%). Right sided injury was observed in 29 patients $(61.7 \%)$, left sided injury in 16 patients (34.0\%) while bilateral injuries were seen in 2 patients (4.3\%). Regarding site of injury proximal ureteric injuries were the most common accounting for 32 patients $(68.1 \%)$. Intraoperative diagnosis was the most common time for diagnosis seen in 30 patients (63.8\%). The endoscopic urological surgeries were the most common cause of urological iatrogenic ureteric injury accounts for $71.4 \%$ of cases. Open upper tract surgeries were responsible for 8 cases $(14.2 \%)$. One patient sustained proximal ureteric injury during retro-peritoneal lymph node dissection (RPLND). Laparoscopic urological surgeries were responsible for four cases of injury. One patient developed ureteric avulsion. 13 patients presented with late Ureteric stricture. We have five nephrectomies while three patients needed permanent nephrostomies. Our success rate was $83 \%$. Conclusions: Endo-urological procedures are the commonest causes of ureteric injuries in our study. Prompt diagnosis and early corrective intervention can result in satisfactory outcome in about $83 \%$ of cases.

Key words: $\quad$ latrogenic, Management, Ureteric Injuries, Urological.

Article Citation: Mansoor M. latrogenic ureteric injuries in urological surgeries- a tertiary hospital experience. Professional Med J 2020; 27(12):2558-2563. https://doi.org/10.29309/TPMJ/2020.27.12.5378

\section{INTRODUCTION}

latrogenic ureteric injury is defined as any inadvertent injury to the ureter during any surgical procedure in or around the ureter which necessitated an additional period of observation or intervention either endoscopic or open surgery. ${ }^{1}$ latrogenic ureteric injuries are rare complication of any difficult abdamino -pelvic surgical procedures. These are associated with high morbidity due to risk of infection and possible loss of renal function. Gynecological and colorectal surgeries are commonly associated with the risk of iatrogenic ureteric injuries as the ureter run close to the field of dissection..$^{2,3}$

Traditionally, latrogenic ureteric injuries are often blamed as a result of non-urological operations especially to gynecological and colorectal operations. ${ }^{4}$ However the urologist are also equally responsible for this threat. In last two decades, the advancement in urology and performance of more complex minimally invasive endoscopic procedure like Uretero-renoscopy (URS) with Lithoclast, use of dormia basket, endo-pylotomyetc results in increased risk of ureteric injuries. The use of rigid ureteroscope was blamed as the most common cause of ureteric injury in various literature. ${ }^{5}$ Many common open operations like pyelo-lithotomy and pyeloplasty can also end up with stricture of ureter or pelvi-ureteric junction. ${ }^{6}$ The current trends of laparoscopic urological procedures in and around ureter like partial nephrectomy, retroperitoneal lymphadenectomy, radical cystectomy, pyelo- 
plasty and ureterolithotomy account for some cases of iatrogenic ureteric injury. ${ }^{5}$

Most of published literature on this topic are covering on over all details of iatrogenic ureteric injuries and focusing more on gynecological and general surgical causes. Therefore it is important to look at the urological causes of iatrogenic ureteric injuries in details and its consequences. The purpose of this study is to review our experience in the management of iatrogenic ureter injuries caused by different urological procedures, its various clinical presentation, timing of presentation, site of ureteric injury, type of ureteric injury and method of repair and over all outcomes.

\section{MATERIAL \& METHODS}

This was a descriptive case series conducted in the Department of Urology, Jinnah Postgraduate Medical Centre, Karachi. We analyzed the data of 47 patients having 57 different iatrogenic injuries from January 2011 to December 2018, with minimum of one year follow- up. We included all cases of iatrogenic ureteric injuries experienced in our urology department only. Gynecological and general surgical iatrogenic injuries were excluded in this study. All pertinent details like indication for surgery, type of surgery, location of injury, laterality, type of injury, time of recognition of injury (i-e intra-operative, early and late), treatment modality and their surgical outcomes were recorded.

The recognition time of injury was arbitrarily divided into: intraoperative, early and late. ${ }^{1} \mathrm{An}$ intra-operative recognition is defined as awareness during surgery, while an Early recognition Is usually between days to weeks and manifested as increased urinary drain output, prolonged ileus, urinoma etc. This was diagnosed on the basis of clinical presentation and confirmed by ultrasonography, intravenous urography or CT-urogram. Late presentation came after months to year and present as hydronephrosis, stricture and non- functional kidney. An intervention was defined successful when there were no anastomosis/procedural related complication noted and preservation of ipsi-lateral renal function. Follow up was made in outpatient department with history and examination along with early ultrasound Kidney on two monthly interval, for early detection of hydronephrosis. Intravenous urography (IVU) or CT urogram was performed in selected cases after six months to exclude ureteric stricture and to assess ipsi-lateral renal function. Data were analyzed using Statistical Package for the Social Sciences (SPSS, Version 20.0). For categorical variables, frequency (percentage) was used, and for continuous variables mean \pm SD was calculated.

\section{RESULTS}

There were 56 iatrogenic ureteric injury cases in 47 patients were recorded and managed in our unit during last eight years of study period. Age ranges between 23 - 65 years and the mean age was $43.14+8.86$ years. There were 31 males (66\%) and 16 females (34\%). Mean follow up was 2.6 years. Right sided injury was observed in 29 patients $(61.7 \%)$, left sided injury in 16 patients (34.0\%) while bilateral injuries were seen in 2 patients $(4.3 \%)$. Regarding site of injury proximal ureteric injury including the pelvi-ureteric junction was the most common accounting for 32 patients $(68.1 \%)$, while the middle ureteric injury was seen in 6 patients (12.8\%), and the distal ureteric injury was observe 9 patients (19.1\%). Intraoperative diagnosis was the most common time for presentation seen in 30 patients $(63.8 \%)$, while early presentation with in first 2 weeks of injury was observed in only 4 patients (8.5\%). Late presentation with hydronephrosis and ureteric stricture was observed in 13 patients (27.6\%).

The endoscopic urological surgeries were the most common cause of urological iatrogenic ureteric injury accounts for 40/56 injuries (71.4\%). Ureteric stone disease managed with URS and lithoclast accounting for 24 injuries (42.8\%). Difficult ureteroscopy and DJ placement was responsible for ureteric injury in another 16 patients $(28.5 \%)$. Failure to identify ureteric orifice, incidental ureteric stricture, and big abdominal or pelvic masses with distorted ureteric anatomy were the key factors responsible for these injuries. Al most all of them were managed with 
minimal invasive methods like prolonged ureteric stenting and percutaneous nephrostomy. Open upper tract surgeries like difficult pyelolithotomy, nephrolithotomy and pyeloplasty procedures were responsible for 8 cases (14.2\%). Out of which 4 were presented early as increase urinary drain discharge. Two were responded with DJ placement while 2 patients ultimately ended up with nephrectomy as stenting was difficult or not successful in these patients. Four patients presented late with hydronephrosis and PUJ/proximal ureteic stricture disease. Two responded with DJ stenting while remaining 2 patients was found to have non-functioning kidney and ultimately needed nephrectomy. One patient sustained proximal ureteric injury during retro-peritoneal lymph node dissection (RPLND) as a part of testicular tumor management. He was diagnosed intra-operatively and repair after putting the DJ stent.

Laparoscopic ureterolithotomy was responsible for two cases of ureteric injury. The first case presented as partial ureteric transection during difficult proximal ureteric mobilization. This was closed after stone removal and DJ stent placement. Patient recovered inadvertently. The second case present as stricture ureter six months after surgery and needed prolong DJ stenting and eventually recovered. Another patient came after 3 month of laparoscopic pyeloplasty as hydronephross, for which percutaneous nephrostomy was placed. His antegradenephrostogram showed PUJ stricture. He is still on follow-up. During the study period we have encountered 4 cases of left sided hydronephrosis and hydroureter with stricture ureter in patients who had underwent ileal conduit formation due to bladder growth. All were managed with percutaneous nephrostomy. Their MAG-3 renal scans revealed non-functioning kidneys in 2 cases. Nephrectomy was planned but not performed due to poor fitness of patient and disease advancement. Ante-grade ureteric stenting were performed successfully in remaining two patient with better functioning kidney, and they improved clinically.

One patient developed ureteric avulsion due to difficult Ureteroscopy over a tight proximal ureter (Stricture). Urgent exploration and open nephrostomy was done. But his hematuria did not settled and ultimately needed nephrectomy. The types of various ureteric injuries are shown in Table-I.

Among the 13 patients presented with late Ureteric stricture, only three had history of difficult ureteroscopy and lithoclast. While 4 were due to open surgery, another 4 were associated with ileal conduit formation and one each due to laparoscopic ureterolithotomy and pyeloplasty. Mostly they were managed with DJ stenting and percutaneous nephrostomy. Only one patient with long distal ureteric stricture with functioning kidney needed ureteric re-implantation with psoas hitch, while nephrectomy was performed in two patients. The various operative interventions performed are mentioned in Table-II.

Regarding success rate, we have five nephrectomies, three patients have almost permanent nephrostomies including two postoperative patients with carcinoma urinary bladder with ileal conduit. But remaining 39 out of 47 patients were completely recovered. This makes around $83 \%$ success rate of this study.

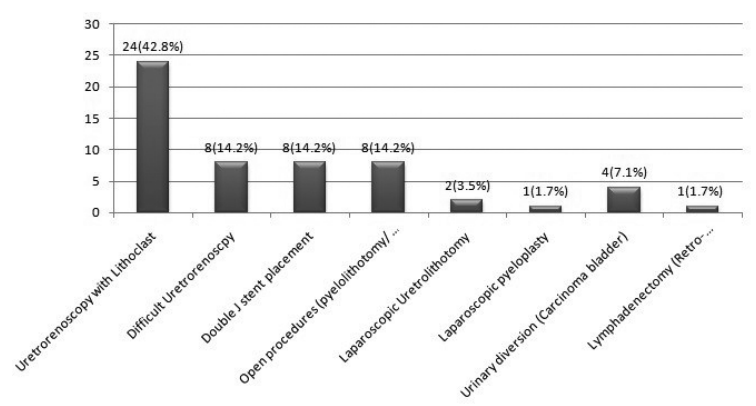

Figure-1. Causes of latrogenic ureteric injuries in urological surgeries

\begin{tabular}{|l|c|c|}
\hline Types of Ureteric Injury & Number & Percentage \\
\hline Significant Mucosal Injury & 25 & $25.5 \%$ \\
\hline False passage & 12 & $17.02 \%$ \\
\hline Perforation & 10 & $12.76 \%$ \\
\hline Ureteric Transection & 6 & $14.89 \%$ \\
\hline Ureteric Ligation & 2 & $17.02 \%$ \\
\hline Ureteric Avulsion & 1 & $2.12 \%$ \\
\hline Total & 56 & \\
\hline
\end{tabular}

Table-I. Types of ureteric injuries 


\begin{tabular}{|l|c|c|}
\hline \multicolumn{1}{|c|}{ Treatment } & Number & Percentage \\
\hline $\begin{array}{l}\text { Early ureteric stenting (open } \\
\text { end ureteric catheter/ Double } \\
\text { J stent) }\end{array}$ & 32 & $68 \%$ \\
\hline Percutaneous Nephrostomy & 17 & $36.1 \%$ \\
\hline End to end anastomosis & 1 & $2.1 \%$ \\
\hline $\begin{array}{l}\text { Ureteric Re-implantation with } \\
\text { Psoas Hitch }\end{array}$ & 1 & $2.1 \%$ \\
\hline Nephrectomy & 5 & $10.6 \%$ \\
\hline \multicolumn{1}{|l|}{ Table-II. Operative procedures performed } \\
\hline
\end{tabular}

\section{DISCUSSION}

latrogenic injury is the most common cause of damage to the ureter, accounting for about $75 \%$ of all ureteric injuries. ${ }^{7}$ Only few studies described that major bulk of reported ureteric injuries are caused by Urologist rather than those by general surgeons or gynecologist. ${ }^{8}$ Most of current published literature reported that gynecological surgeries as the most common cause of ureteric injuries. This attribute to increased practice of minimally invasive surgeries in the specialty. ${ }^{1}$ There are many differences in the result of present study focusing only on urological ureteric injuries, with other studies including obstetric and gynecological procedures also. In present study males are affected more than females with male: female ratio is $66 \%: 34 \%$. This is almost reverse in other studies including gynecological cases with the male/female ratio is $38 \%: 62 \%$. Regarding site of injury, our study showed proximal ureteric injury in $68.1 \%$, middle represents $12.8 \%$ and distil injuries were $19.1 \%$. Similar result were also showed by one study, focusing on urological cases only by Romero $\mathrm{V}$ et al representing $51 \%$ proximal, $14 \%$ middle and $35 \%$ distil ureteric injuries. ${ }^{5}$ Studies including gynecological cases, showed distil ureter as the most vulnerable site for iatrogenic injury with the ratio of upper, middle and lower third of the ureters in $2 \%, 7 \%$ and $91 \%$ of cases. ${ }^{9}$

The use of rigid ureteroscopeis the most common cause of iatrogenic ureteric injuries in our study representing $71.4 \%$ of total cases. These included stone lithoclast, difficult ureteroscopy and double $\mathrm{J}$ stent (DJ) placement and other procedures. Mucosal injuries, and false passages were more common in distal ureter and usually due to placement of open ended ureteric and guide wire insertion in difficult to identify ureteric orifice. Proximal ureteric injuries are more serious especially with impacted ureteric stone and comprises of perforation and avulsion. Proximal tortuosity of ureter due to stone obstruction and distal narrowing (stricture) further aggravate the problem during ureteroscopy. Similar results were also shown in another study by Romero $\mathrm{V}$ et al showed that $85 \%$ of major ureteric injuries were caused by ureteroscopic stone removal. ${ }^{5}$ But fortunately almost all improved with minimal access procedures. In present study only 3 of them presented as late ureteric stricture needed further treatment. Moreover most of the urological ureteric injuries were diagnosed intra-operatively in our study (63.8\% cases). This observation was also observed by Selzman et al, stated that injuries sustained during urological procedures were commonly identified intra-operatively and managed with insertion of a ureteric stent. $^{9}$ Lask et al demonstrated that placement of a percutaneous nephrostomy (PCN) alone allowing up to $80 \%$ of injured ureter to recover patency. ${ }^{10}$ Similar observation was noted by Jassica Morrow et al stating that only one major delayed recognize ureteric injury resulting from urological surgeries versus 20/21 injuries occur non-urological procedures. ${ }^{11}$

About $70 \%$ of our ureteroscopic injuries occur in first half of our study (2011-2014). At that time the only available endoscopic treatment option for big proximal ureteric stone was rigid ureterscope of $9.5 \mathrm{~F}$ size. But from 2015 onwards we started using small caliber semi rigid ureteroscope of size $6.5-7.5 \mathrm{~F}$. This reduces the ureteric injuries rate in our study. Similar results were shown by Ono et al in 1989. His study reported ureteric avulsion $(0.5 \%)$, perforation $15 \%$ along with stricture as well as asymptomatic grade -1 VUR by using older $11.5 \mathrm{~F}$ rigid uretroscope. ${ }^{12}$ In another study by Murtuyn et al in 1997 using 7.2 F instrument showed mucosal injury only $1.6 \%$, no perforation with no case of avulsion. So miniaturization of ureteroscope can decreased the chances of ureteric injuries as small caliber endoscope is less traumatic. ${ }^{13}$ Now a days with the advent of 
flexible ureteroscope and durable access sheets, the ureteric injury becomes a rare event. A study of 150 cases with the use of $12 / 14 \mathrm{~F}$ access sheet revealed only a single ureteral stricture. ${ }^{14}$

In our study we have four cases of laparoscopic ureteric injuries encountered during laparoscopic ureterolithotomy and pyelo-plasty. They were managed and recover well. Over the past 20 years, there has been a rapid uptake of laparoscopic and robotic techniques in urology and other surgical specialties. This has increased the risks of injury to the ureter. ${ }^{15}$ Laparoscopic gynaecological surgery is now responsible for the highest rate of ureteric injuries (64\%), compared with $26 \%$ for general surgery and $11 \%$ for urological procedures. ${ }^{16}$ Parpala-Sparman and colleagues from Finland analyze ureteric injuries at their institution during three different time periods : 1986- 1992, 1993-1999 and 2000-2006. They reported that iatrogenic ureteric injuries significantly increased over time and this was associated with laparoscopic gynecological procedures but not due to ureteroscopic intervention. ${ }^{16}$ One recent study about laparoscopic gynecological surgeries reported that incidence of all major complications are declining, but the ureteric injury incidence has stayed constant at approximately $1 \% .{ }^{17}$ Another study of uterine prolapse surgery also reported that hydronephrosis associated with obstructiveuropathy may lead to a tortuous ureter which place the ureter in non-anatomical position and prone it for more risk of injury. ${ }^{18}$ Limitation of injury can be achieved by intimate knowledge of the pelvic anatomy, careful visualization and palpation of ureter and in some instances by prophylactic ureteric stenting. ${ }^{19}$

During the study period we had operated 35 patient of transitional cell Carcinoma urinary bladder with ileal conduit. Out of them four developed left sided hydronephrosis with stricture ureter. This may be related to ureteric ischemia secondary to extensive left ureteric mobilization and kinking of ureter during its passage behind the mesentery of descending colon. Success rate of our study is around $83 \%$, which is slightly lower than other studies showing $94 \%$ success rate. ${ }^{4}$
Regarding the preventive aspect of injuries, different methods have been used for intraoperative ureteric identification during surgeries. Ureteric stenting has been employed for long. But literature showed that prophylactic ureter stenting will not prevent ureteric injury, but it allow early identification of injury. ${ }^{20}$ It have many disadvantages like increased operating time and $\operatorname{cost}^{21}$, more hospital stay, risks of radiation and higher chances of infection and haemituria. $^{22}$ Recently lighted ureteric stents (LUS) has been used with success in colorectal surgeries with excellent results of no injury in 465 patients. $^{21}$ Recent literature recommend the technique of intravenous methylene blue fluorescence in highlighting ureters in patients undergoing open and laparoscopic surgeries around uretes. ${ }^{23,24}$ Indocyanine green (ICG) was also used as substitute for methylene blue. Its technique is retrograde intra-ureteric injection of ICG and visualization under near-Infrared (NIR) fluorescent light aided in ureteric delineation and differentiating between healthy and diseased tissue. ${ }^{25}$

\section{CONCLUSIONS}

As long as surgeons operate near the ureters the potential for iatrogenic ureteric injury will exist and require a dynamic approach for management. Endo-urological procedures are the commonest causes of ureteric injuries in our study. Prompt diagnosis and early corrective intervention can result in satisfactory outcome in about $83 \%$ of cases.

Copyright@ 03 Aug, 2020.

\section{REFERENCES}

1. Chalya PL, Massinde AT, Kihunrwa A, Simbila S. latrogenic ureteric injuries following abdominopelvic operation: A 10-year tertiary care hospital experience in Tanzania. World J Em Surg. 2015 10:17 Dol 10. 1186/s 13017-015-0011-z.

2. Polat O, Gul O, Aksoy Y, Uzbey I, Demirel A. Iatrogenic injuries to ureter, bladder and urethra during abdominal and pelvic operations. Int Urol Neprol 1997; 29(1):13-8.

3. Rafique M, Arif HM. Management of iatrogenic ureteric injuries associated with Gynecological surgery. Int Urol Nephrol 2002; 34:31-5. 
4. Al-Awadi K, Kehinde EO, Al-Hunayan A, Al-Khayat A. latrogenic Ureteric Injuries: Incidence, Aetiological factors and the effect of early management on subsequent outcome. Int Urol Nephrol 2005; 37:23541.

5. Romero V, Akpinar H, Smith JJ, Assimos DG. Changing patterns in iatrogenic ureteric injuries. Reviews in Urol 2011; 13(4):179-83.

6. Persky L, Krause JR, Boltuch RL. Initial complications and late results of dismembered pyeloplasty. J Urol 1977; 118:162-8.

7. Dobrowolski Z. Renal and ureteric trauma: Diagnosis and management in Poland. BJU Int. 2002; 89:748-51.

8. Smith AD. Management of iatrogenic ureteric strictures after urological procedures. J Urol. 1988; 140:1372-74.

9. Selzman $A A$, Spirnak JP. latrogenic ureteral injuries: A 20-year experience in treating 165 injuries. J Urol.1996; 155:878-81.

10. Lask D, Abarbanel J, Luttwak Z. Changing trends in management of iatrogenic ureteric injuries. J Urol. $1995 ; 154: 1693-5$.

11. Morrow J, Curry D, Dooher M and Woolsey S. Minimally invasive management of delayed recognition iatrogenic ureteric injury. Ulster Med J. 2017; 86(3):181-4.

12. Ono Y, Ohshima S, Kinukawa T, Matsuura O, Hirabayashi $\mathrm{S}$, Yamada S. Long-term results of transurethral lithotripsy with the rigid ureteroscope: Injury to the intramural ureter. J Urol. 1989; 142: 958-60.

13. Murthyn PV, Gurunadha HS, Meherwade S, Srinivasa Rao PVLN, Srivastava A, Sasidharan K. Ureteroscopic lithotripsy using mini-endoscope and Swiss Lithoclast: Experience in 147 cases. J Endourol. 1997; 11: 327-30.

14. Stern J, Yiee J, Park S. Safety and efficacy of ureteral access sheaths. J Endourol. 2007; 21: 119-23.

15. Abboudi H, Ahmed K, Royle J, Khan MS, Dasgupta P. Ureteric injury: A challenging condition to diagnose and manage. Nature Review Urology. 2013; 10(2): 10815.
16. Parpala-Sparman T, Paananen I, Santala M, Ohtonen P, Hellstrom $P$. Increasing numbers of ureteric injuries after the introduction of laparoscopic surgery. Scand. J. Urol Nephrol. 2008; 42:422-7.

17. Nerli RB, Ghangane SC, Kadeli V, Hiremath MB. Ureteric injuries during laparoscopic gynecological surgeries. J Sci Soc.2019; 46: 3-7.

18. Smith AP, Bazinet $A$, Liberman D. latrogenic ureteral injury after gynecological surgery. CanUrol Assoc. 2019; 13 (6 suppl4):551-5.

19. Monodoro S, Frigerio M, Milani R. Tips and tricks for uterosacral ligament suspension: How to avoid ureteral injury. Int Urogynecol J. 2018; 29:161-3.

20. Da Silva G, Boutros M, Wexner SD. Role of prophylactic ureteric stents in colorectal surgery. Asian J Endosc Surg. Aug 2012; 5(3): 105-10.

21. Boyan WP Jr, Lavy D, Dinallo A, Otero J, Roding A, Hanos D, Dressner R, Arvantis M. Lighted ureteral stents in laparoscopic colorectal surgery; A five year experience. Ann Transl Med. 2017; 5(3):44.

22. Speicher PJ, Goldsmith ZG, Nussbaum DP, Turley RS, Peterson AC, Mantyh CR. Ureteral stenting in laparoscopic colorectal surgery. J Surg Res. 2014; 190: 98-103.

23. Yeung TM, Volpi D, Tullis ID, Nicholson GA, Buchs N, Cunningham C, Guy R, Lindsey I, George B, Jones O, Wang LM, Hompes R, Vojnovic B, Hamdy F, Mortensen NJ. Identifying ureters in situ under fluorescence during laparoscopic and open colorectal surgery. Ann Surg. 2016; 263: e1-e2.

24. Al-Taher M, van den Bos J, Schols RM, Bouvy ND, Stassen LP. Fluorescence ureteral visualization in human laparoscopic colorectal surgery using methylene blue. J Laparoendosc Adv Surg Tech A. 2016; 26:870-875.

25. Lee Z, Simhan J, Parker DC, Reilly C, Llukani E, Lee DI, Mydlo JH, Eun DD. Novel use of indocyanine green for intraoperative, real-time localization of ureteral stenosis during robot-assisted ureteroureterostomy. Urology. 2013 sep; 82(3): 729-733.

\section{AUTHORSHIP AND CONTRIBUTION DECLARATION}

\begin{tabular}{|c|c|c|}
\hline Sr. \# & Author(s) Full Name & \multicolumn{1}{|c|}{ Contribution to the paper } \\
\hline 1 & Muhammad Mansoor & $\begin{array}{l}\text { Conception and design, Statistical } \\
\text { expertise, Critical revision of the } \\
\text { article for important intellectual } \\
\text { content. }\end{array}$ \\
\hline
\end{tabular}

